\title{
GESTÃO DA EDUCAÇÃO ESPECIAL NO BRASIL E CONSERVADORISMO POLÍTICO: NOTAS SOBRE UMA HISTÓRIA PERSISTENTE
}

\author{
Special education management in Brazil and political conservatism: notes about a \\ persistent history
}

\author{
Gestión de educación especial en Brasil y conservadurismo político: notas sobre \\ una historia persistente
}

\begin{abstract}
Resumo
Neste artigo temos por objetivo analisar as alterações na organização da gestão da Educação Especial entre 1986 e 2020, período considerado democrático pela historiografia, mas que conserva estruturas administrativas com origem na ditadura militar. Os procedimentos metodológicos consistiram em pesquisa documental com contribuições da análise de discurso. Foram verificadas algumas características na Educação Especial brasileira, como a conformação de seu lugar na estrutura administrativa do Estado brasileiro e a presença constante das instituições privado-assistenciais na proposição dos órgãos gestores e nas diretrizes de Educação Especial. Conclui-se que o diálogo entre a administração pública e setores privados, como sociedade civil organizada, por um lado pode ser analisada como característica de processos democráticos, em que se espera a existência de disputas nas tomadas de decisão. Por outro, pode ser indicativo de uma posição conservadora de manutenção de dependência econômica das instituições privadas aos recursos públicos.
\end{abstract}

\footnotetext{
${ }^{*}$ Graduação em Matemática-Licenciatura, mestrado em Educação e doutorado em Educação pela Universidade Federal de Mato Grosso do Sul. Pós-doutorado pela Universidade Federal da Grande Dourados. É editora associada da Revista Brasileira de Educação Especial (Associação Brasileira de Pesquisadores em Educação Especial - ABPEE). Membro representante da região Centro-Oeste na Comissão Editorial da Revista Brasileira de Educação - RBE. Colaboradora do Grupo de Trabalho (GT 15) Educação Especial da Associação Nacional de Pós-graduação e Pesquisa em Educação (ANPEd). É coordenadora do GT 15 (Educação Especial) da ANPEd Centro-Oeste. Professora adjunta da Universidade Federal de Mato Grosso do Sul. Endereço profissional: Universidade Federal de Mato Grosso do Sul, Campus do Pantanal, Rua Domingos Sahib Cervejaria CEP 79300130 - Corumbá, MS Brasil - Caixa-postal: 252. Contato profissional: (067) 3234-6215. URL da Homepage: creia.ufms.br. Email: andressarbl@gmail.com Orcid: https://orcid.org/0000-0003-1873-5622.

** Graduação em Pedagogia pela Universidade Estadual de Campinas. Mestrado em Educação pela Universidade Federal de Mato Grosso do Sul e doutorado em Educação pela Universidade Estadual de Campinas. Pós-doutorado na Universidad de Alcalá. Pós-doutorado na Universidade Estadual de Campinas. Pós-doutorado na Universidade de Lisboa. Professora Titular pela Universidade Federal de Mato Grosso do Sul e Pesquisadora Sênior Voluntária da mesma universidade, onde atua no Programa de Pós-graduação em Educação - Educação Social, no Campus do Pantanal. Endereço profissional: Universidade Federal de Mato Grosso do Sul, UFMS - Campus do Pantanal, Departamento de Educação, Rua Domingos Sahib, 99 Cervejaria 79301000 - Corumbá, MS - Brasil. Contato profissional: (67) 32346214. URL da Homepage: http://ppeees.ufms.br/. E-mail: monica.kassar@gmail.com Orcid: https://orcid.org/0000-0001-5577-6269.
} 
PALAVRAS-CHAVE: Educação Especial. Inclusão escolar. Conservadorismo.

\begin{abstract}
In this article we aim to analyze changes in the organization of the Special Education management between 1986 and 2020, a period considered democratic by historiography, but which preserves administrative structures originated from the military dictatorship. The methodological procedures consisted of documentary research with contributions from discourse analysis. Some characteristics in the Brazilian Special Education were verified, such as the conformation of its place in the administrative structure of the Brazilian State and the private-assistance institutions constant presence in the proposal of the management public sectors and in the Special Education guidelines. It is concluded that the relation between public administration and private sectors as organized civil society, on the one hand, can be analyzed as a characteristic of democratic processes in which disputes are expected in decision-making. On the other hand, it may be a indication of a conservative position to maintain the private intitutions economy dependent on public resources.
\end{abstract}

KEYWORDS: Special Education. School Inclusion. Conservatism.

\title{
Resumen
}

En este artículo objetivamos analizar las alteraciones en la organización de la gestión de la Educación Especial entre 1986 y 2020, período considerado democrático por la historiografía, pero que conserva estructuras administrativas originarias en la dictadura militar. Los procedimientos metodológicos consistieron en investigación documental con contribución del análisis del discurso. Fueron verificadas alunas características en la Educación Especial brasileña, como la conformación de su espacio en la estructura administrativa del Estado brasileño y la presencia constante de las instituciones privado-asistenciales en la proposición de los órganos gestores en las directrices de Educación Especial. Se concluye que el diálogo entre la administración pública y sectores privados, como sociedad civil organizada, por un lado, puede ser analizada como característica de procesos democráticos, en que se espera la existencia de disputas en las tomas de decisión. Por otro, puede ser indicativo de una posición conservadora de manutención de dependencia económica de las instituciones privadas a los recursos públicos.

PALABRAS CLAVE: Educación Especial. Inclusión Escolar. Conservadurismo.

\section{INTRODUÇÃO}

Ao longo da história da Educação Especial no Brasil existiram diferentes órgãos gestores de suas políticas, que variaram de órgãos autônomos a diretorias dentro de secretarias, vinculadas à pasta Educação: o Centro Nacional de Educação Especial (CENESP), criado em 1973; a Secretaria de Educação Especial criada em 1986; a Secretaria de Educação Continuada, Alfabetização, Diversidade e Inclusão (SECADI), a partir de 2011; a Secretaria de Modalidades Especializadas de Educação, criada em 2019.

Em todo esse período, uma das alterações mais significativas talvez tenha sido a extinção da Secretaria de Educação Especial e a incorporação da Educação Especial pela SECADI, em 2011, pois marca a mudança de perspectiva na organização de sua gestão. Bueno (2016, p. 176) afirma que essa alteração parece constituir um avanço, na medida em que inclui a Educação Especial "dentro de um âmbito mais largo, da 
diversidade social e das consequentes políticas de inclusão, desenvolvidas por meio de um conjunto de programas e ações".

Também se deve registrar o questionamento realizado naquele momento sobre a possibilidade de uma Diretoria de Educação Especial no âmbito da SECADI, em meio a ações explicitadas no contexto da "educação inclusiva", atender à especificidade da Educação Especial, que demanda políticas de atendimento especializado específicas (KASSAR, 2014).

Para compreender mudanças pontuais é necessário ver a organização da política de Educação Especial em seu conjunto mais amplo. Com esse intuito, neste artigo temos por objetivo analisar as alterações na organização da gestão da Educação Especial entre 1986 e 2020, período considerado democrático pela historiografia, mas que conserva estruturas administrativas com origem na ditadura militar. No período, podem ser identificados avanço e disseminação de uma "restauração conservadora", como denominado por Apple (2002), em que "neo-liberais, os neo-conservadores, os populistas autoritários e uma fracção particular de uma nova classe média em ascensão" ganham evidência (APPLE, 2002, p. 57).

O conservadorismo revela-se, também, na educação, seja no ataque às suas instituições públicas (especialmente escolas e universidades), vistas como "“buracos negros' nos quais o dinheiro é investido - e aparentemente desaparece - e que não conseguem providenciar resultados adequados" (APPLE, 2002, p. 77), ou na sua organização pedagógica, curricular, ideológica (CORREIA, 2013).

Algumas características podem ser identificadas como movimento conservador. $\mathrm{Na}$ perspectiva pedagógica, autores o identificam em formas educativas que levem à tentativa de manutenção de um status quo (SAVIANI, 1985; LIBÂNEO, 1990; CORREIA, 2013). Como política educacional, o conservadorismo pode ser constatado na racionalidade econômica, na busca da eficiência e da "ética" da análise de custolucro (APPLE, 2002), na defesa da educação domiciliar (ALVES JUNIOR; TROVÃO, 2019), entre outros.

Os procedimentos metodológicos consistem em pesquisa documental com contribuições da análise de discurso (BAKHTIN, 1992; ORLANDI, 2005).

\section{Secretaria de Educação Especial: transformações democráticas em curso}

Durante o governo militar de Emílio Garrastazu Médici (1969-1974) é criado na estrutura do Ministério da Educação e Cultura o CENESP. Esse órgão gestor da Educação Especial permanece durante os governos de Ernesto Geisel (1974-1979) e de João Baptista Figueiredo (1979-1985). A participação das instituições privadoassistenciais é marca da gênese da Educação Especial como política pública, influenciando a criação e a gestão desse órgão (JANNUZZI, 2004; KASSAR, REBELO; JANNUZZI, 2019). A forte presença dessas instituições e a configuração "complementar" entre os atendimentos público e privado de Educação Especial no país são focos de estudos na literatura (JANNUZZI, 1997; MAZZOTTA, 2001). Dentre as críticas referentes às suas ações, ressalta-se a perspectiva assistencialista, afastada de propósitos educacionais e escolares (BUENO, 2004; MELETTI, 2006).

$\mathrm{Na}$ transição democrática, cria-se um "Comitê para o Aprimoramento da Educação Especial" para no prazo de 180 dias propor um plano nacional "com a missão 
abrangente de estudar todos os aspectos do problema, com a participação de vários setores do Governo, bem como de entidades" (BRASIL, 1985a, p. 4). Em 1985, o presidente eleito indiretamente por Colégio Eleitoral, José Sarney (que assumiu a Presidência devido ao falecimento de Tancredo Neves, titular da candidatura) em seu discurso Redefinição da educação especial na solenidade de assinatura do decreto que instituiria o Comitê, afirmou que

\begin{abstract}
[...] várias iniciativas, embora incipientes, já foram feitas, inclusive com a criação de alguns órgãos com responsabilidade sobre o assunto, e alguns instrumentos legais [...]. No entanto, os órgãos têm trabalhado descoordenadamente, os recursos são escassos, há aspectos que não são tocados, leis não-aplicadas, não-cumpridas [...]. Anuncio agora meu desejo, solenemente, de marcar meu governo como o ponto de não-retorno do problema (BRASIL, 1985a, p. 3).
\end{abstract}

A despeito da declarada intenção de não repetir problemas característicos da Educação Especial até então, em seu discurso, o presidente não apresenta a questão necessariamente como reivindicação de direitos, mas como "um problema de bondade" (BRASIL, 1985b), o que remete às históricas ações de filantropia e assistência.

O fim do CENESP pode ser entendido como uma forma de "finalização" das ações do regime militar para a Educação Especial. O novo governo que se instalava por uma eleição indireta precisava demonstrar que, ao menos administrativamente, era diferente dos governos anteriores. Adequar o aparelho estatal a essa nova conjuntura era um passo importante na legitimação do novo governo.

Assim, no ano de 1986 é criada a Coordenadoria Nacional para a Integração da Pessoa Portadora de Deficiência (CORDE) (BRASIL, 1986a) contando com a participação de diversas representações de entidades privadas, subordinada ao Ministro de Estado Chefe do Gabinete Civil, para atuar sob sua direta e imediata supervisão. No mesmo ano, a Secretaria de Educação Especial (SESPE) é criada, "mantida a sua competência e estrutura" no Ministério da Educação (BRASIL, 1986b), anteriormente Ministério da Educação e Cultura (BRASIL, 1973) e o CENESP deixa de existir.

A Secretaria e o CENESP foram igualmente definidos como órgãos centrais de direção superior (BRASIL, 1973, art. $1^{\circ}$; BRASIL, 1986b, art. $3^{\circ}$ ). Entretanto, o CENESP gozava de "autonomia administrativa e financeira, sendo as suas atividades supervisionadas pela Secretaria Geral do Ministério da Educação e Cultura" (BRASIL, 1973 , art. $1^{\circ}, \S$ único), enquanto que esse aspecto não aparece na especificação da SESPE, indicando-se assegurada somente uma "autonomia limitada" ao Instituto Nacional de Educação de Surdos (INES) e ao Instituto Benjamin Constant (IBC), órgãos estes que passam a ser integrantes da Secretaria de Educação Especial (SESPE) (BRASIL, 1986b, art. 6).

No ano seguinte, em 1987, foi criado o Conselho Consultivo da CORDE, a fim de opinar sobre o desenvolvimento da Política Nacional para Integração da Pessoa Portadora de Deficiência, apresentar sugestões para o encaminhamento dessa política e responder a consultas formuladas pela Coordenadoria. Estabeleceu-se que o Conselho Consultivo deveria ter a seguinte composição: Ministro-Chefe da Secretaria de Planejamento e Coordenação da Presidência da República, na condição de Presidente; Coordenador da Corde/Seplan/PR, como Secretário-Executivo e substituto do Presidente do Conselho, em seus impedimentos; representante do Ministério da Educação; quatro representantes do Ministério da Previdência e Assistência Social, sendo: a) um representante da Legião Brasileira de Assistência; b) um representante da 
Fundação Nacional do Bem-Estar do Menor; c) um representante do Instituto Nacional de Assistência Médica da Previdência Social; e d) um representante do Instituto Nacional de Previdência Social. Um representante do Ministério do Trabalho; e um representante do Ministério da Saúde (BRASIL, 1987, art. $2^{\circ}$ ).

Igualmente comporia a representação seis representantes de instituições interessadas: o Presidente da Federação Brasileira de Entidades de Cegos; o Presidente da Federação Brasileira das Instituições de Excepcionais; o Presidente da Federação Nacional das Associações de Pais e Amigos dos Excepcionais; o Presidente da Federação Nacional das Sociedades Pestalozzi; o Presidente da Federação Nacional de Educação e Integração dos Surdos; e o Presidente de Organização Nacional das Entidades de Deficientes Físicos. Os representantes dos Ministérios seriam indicados pelos respectivos ministros, com delegação de competência para responder pelo Ministério com relação aos assuntos pertinentes à pessoa com deficiência (BRASIL, 1987, art. $2^{\circ}$ ).

Em relação aos movimentos sociais de pessoas com deficiências, Jannuzzi (2004) afirma que, assim como nos anos 1950, a década de 1980 foi significativa, sendo criada em 1984 a Federação Brasileira de Entidades de Cegos (Febec), a Organização Nacional de Entidades de Deficientes Físicos (Onedef), a Federação Nacional de Educação e Integração de Surdos (Feneis) e o Movimento de Reintegração dos Hansenianos (Morhan). Em dezembro do mesmo ano, foi fundado o Conselho Brasileiro de Entidades de Pessoas Deficientes, que reuniu as quatro entidades e substituiu a Coalisão Nacional organizada em Brasília em $1980^{\dagger}$, em seu primeiro encontro nacional. O Conselho Brasileiro de Entidades de Pessoas Deficientes atuou até 1986. Aos poucos esses movimentos foram integrando-se internacionalmente. Assim o Onedef passou a representar a área de deficiência junto ao Disabled People International (DPI) por meio do seu Conselho Latino-Americano. Os cegos vincularamse à União Mundial dos Cegos (OMC) e à União Latino-Americana dos Cegos (Ulac); os surdos, pela Feneis, ligaram-se ao World Federation of Deef. Segundo a autora, vão assim ampliando também as suas visões dos problemas.

Mobilizações como essas repercutem na promulgação da Constituição Federal em 1988 (LANNA JUNIOR, 2010), que estabelece que "o dever do Estado com a educação será efetivado mediante a garantia de: [...] atendimento educacional especializado aos portadores de deficiência, preferencialmente na rede regular de ensino" (BRASIL, 1988, art. 208, III). Nesse documento optou-se por um federalismo cooperativo sob a denominação de regime articulado de colaboração recíproca, descentralizado, com funções privativas, comuns e concorrentes entre os seus entes, incluindo o financiamento da educação (CURY, 2010). A cooperação passa a exigir a participação supondo a abertura de novas arenas públicas de deliberação e mesmo de decisão (CÔRTES, 2007; HOCHMAN, ARRETCHE; MARQUES, 2007).

Os princípios de racionalização dos processos se fariam presentes nos anos 1990 na administração pública brasileira através da Reforma do Aparelho do Estado (BRASIL, 1995) já mostrando sinais na gestão de Fernando Collor de Mello, com

\footnotetext{
† Tratava-se da "Coalizão Pró-Formação para a Federação Nacional", entidade com "a finalidade de defender os direitos e interesses mais gerais das pessoas deficientes”. Ver: $1^{\circ}$ Congresso Nacional de Pessoas Deficientes, $2^{\mathrm{a}}$ quinzena de outubro de 1980. Boletim 1 - Coalizão Pró-Formação para a Federação Nacional, $\quad$ Brasília, jul $1980 . \quad$ Disponível http://www.memorialdainclusao.org.br/br/exposicoes/tour-virtual/sala-principal/movimentosocial/modulo-3-mobilizacao-nacional/primeira-e-ultima-pagina-do-boletim-pessoa-deficiente-1coalizao-pro-formacao-para-a-federacao-nacional-brasilia-julho-de-1980/. Acesso: 24 abril 2020.
} 
privatizações e abertura econômica ao mercado internacional (SCHNEIDER, 1992). Seguindo a lógica gerencial na organização das autarquias administrativas do Estado, no governo de Fernando Collor de Mello, no início da década de 1990, não temos a SESPE aparecendo na estrutura básica do Ministério da Educação (BRASIL, 1990). Como consequência, a Educação Especial passa a ser responsabilidade da Secretaria Nacional de Ensino Básico (SENEB) no Departamento de Educação Supletiva e Especial (DESE), havendo nele uma Coordenação de Educação Especial (MAZZOTTA, 2001).

Segundo Bezerra e Araújo (2014, p. 104), essa aproximação da Educação Especial com a educação básica, na mesma pasta, revela "historicamente, uma tímida tentativa de se superar a velha dicotomia entre ensino regular e especializado na educação nacional". Para os autores "transparece aí, ao menos em termos administrativo-gerenciais, a ideia de se situar a educação especial como modalidade, transversal às etapas básicas da escolarização formal".

Outra reforma na estrutura administrativa do Ministério da Educação e do Desporto (MEC), efetivada em 1992, recolocou o órgão de Educação Especial na condição de Secretaria, tal como os órgãos de educação fundamental, média e superior (BRASIL, 1994a). O governo Itamar Franco por meio da Lei $n^{\circ}$ 8.490/1992 recriou a Secretaria de Educação Especial (SEESP), que passou a apresentar nova sigla e nova situação na estrutura do MEC (BRASIL, 1992). A Secretaria elabora e implementa a Política Nacional de Educação Especial publicada em 1994 (BRASIL, 1994b) e permaneceria na estrutura do MEC nos governos Fernando Henrique Cardoso e Luiz Inácio Lula da Silva.

A Secretaria de Educação Especial (SESPE e depois SEESP) passou por cinco governos distintos, todos após 1985: José Sarney, Fernando Collor de Mello, Itamar Franco, Fernando Henrique Cardoso e Luiz Inácio Lula da Silva. Em 2011, no governo de Dilma Rousseff a Secretaria foi extinta e a área da Educação Especial foi incorporada por outra secretaria já existente, a Secretaria de Educação Continuada, Alfabetização e Diversidade (SECAD). Todas essas alterações são em sua extensão, marcadas por inúmeras mudanças políticas, econômicas e sociais no país. Para compreender o discurso educacional que as tangenciam é preciso ter em consideração essas transformações.

Com a promulgação da Constituição da República Federativa do Brasil, uma nova forma de organização das políticas sociais brasileiras era vislumbrada por vários setores da sociedade, dada a "vocação" social expressa na letra da lei. Esboçava-se naquele momento um Estado de bem-estar social que não chegou a se consolidar (ALGEBAILE, 2005), embora a Constituição em seu artigo $6^{\circ}$ reconhecesse como direitos sociais a educação, a saúde, o trabalho, a moradia, o lazer, a segurança, a previdência social, a proteção à maternidade e à infância e a assistência aos desamparados (BRASIL, 1988).

Essa direção foi redefinida durante os anos 1990. Os governos de Fernando Collor de Mello (1990-1992) e Itamar Franco (1992-1994) apresentavam traços preparatórios para as ações consideradas mais próximas ao neoliberalismo, nos dois governos de Fernando Henrique Cardoso (1995-2002) (ALGEBAILE, 2005).

O governo Lula (2003-2010), ao chegar ao poder, propunha um "autêntico pacto social" por mudanças e uma aliança que procurasse entrelaçar objetivamente "o trabalho e o capital produtivo" (SILVA, 2003, p. 5). Nesse último governo, em 2008, publicouse a Política Nacional de Educação Especial na Perspectiva da Educação Inclusiva (BRASIL, 2008). O documento foi redigido com a participação da Secretária de 
Educação Especial, da Diretora do Departamento de Política da Educação Especial; de técnicos da Coordenação Geral de Desenvolvimento da Educação Especial e da Coordenação Geral de Articulação da Política de Inclusão e de nove pesquisadores de universidades públicas brasileiras.

À época, a secretária de Educação Especial registrou que este documento correspondia a um avanço quanto ao atendimento à população com deficiência, pois

[...] afirma como diretrizes para a construção dos sistemas educacionais inclusivos, a garantia do direito de todos à educação, o acesso e as condições de permanência e continuidade de estudos no ensino regular. Contribuindo para romper com uma dinâmica social mais ampla de exclusão que historicamente tem condicionado as ações na área. O documento contempla a necessidade de reorientação da educação especial e a articulação dos sistemas de ensino, dando visibilidade às dimensões conservadoras que perpassam o campo da educação e dificultam uma real transformação da escola (Cláudia Pereira Dutra, Secretária de Educação Especial/MEC). (MEC, 2008, p. 1, grifos nossos).

Pode ser verificada, na proposição da Política de 2008, a valorização do espaço público educacional tanto na sua formulação, na medida em que foram convidados para a elaboração do documento pesquisadores de instituições públicas de ensino superior, como em seu conteúdo, na eleição da escola comum - pública - como lócus a priori de todos os alunos.

Uma professora universitária, componente do Grupo de Trabalho (GT) de formulação da Política de 2008, antecipou as dificuldades que seriam enfrentadas em sua implementação: "Isso 'deve' ou 'tem que' provocar uma mudança de mentalidade no âmbito educacional. Mas não vai ser fácil em um país em que o ensino especial foi sempre muito segregado" (Maria Amélia Almeida, professora universitária, membro do GT de formulação da Política de 2008). (MEC, 2008, p. 32).

Esse documento também era visto por um dos participantes em sua elaboração como resultado de intensas lutas, a partir da descentralização da gestão das políticas educacionais:

\footnotetext{
No que se refere ao plano das proposições pedagógicas, temos atualmente um contexto muito diferente daquele de 1994, quando houve a aprovação da anterior Política Nacional de Educação Especial. [...] A política pode ser considerada o movimento que, em 2007, se intensificou e continua nos mobilizando em debates públicos, muitas vezes acirrados, a respeito dos temas que dizem respeito à inclusão. A política ganha corpo e nome ao entendermos que os gestores não têm apenas direito, mas têm obrigação de serem propositivos no que concerne à gestão das diferentes instâncias do sistema educacional (Cláudio Roberto Baptista, professor universitário, membro do GT de formulação da Política de 2008). (MEC, 2008, p. 23).
}

Os depoimentos fazem referência à existência de embates no campo da Educação Especial. Ressalta-se, inclusive, que na formação do grupo-tarefa não há representantes de instituições privado-filantrópicas, presenças constantes na elaboração das políticas de Educação Especial até aquele momento. Sobre os rumos tomados com a proposição do documento de 2008, Eduardo Barbosa, Presidente da Federação Nacional das Associações de Pais e Amigos dos Excepcionais (Apaes) na época, se pronuncia: 


\begin{abstract}
Temos afirmado que qualquer ruptura com o modelo de escola especial, sem considerar a possibilidade de sua desconstrução, reconstrução e/ou ressignificação, é uma arbitrariedade.[...] não devemos permitir que ela [ $a$ política de educação especial na perspectiva inclusiva] se traduza ou se reduza a uma cruzada contra as escolas especiais ou sequer venha a se prestar à desestruturação dessa rede, que por anos se dedicou à construção de propostas educacionais voltadas ao atendimento das distintas especificidades desse segmento populacional expressivo de crianças, adolescentes e jovens estudantes brasileiros. (BARBOSA, 2008, p. 56)
\end{abstract}

A existência de diferentes perspectivas pode explicar tentativas de conciliação nas políticas educacionais. Nos governos de Luiz Inácio Lula da Silva e Dilma Rousseff (2011-2016), as políticas de Educação Especial caracterizaram-se, muitas vezes, por iniciativas de significado difuso, devido aos conflitos com relação às opções de lócus para a escolarização e atendimento às pessoas com deficiência, verificadas, por exemplo, nas alterações sobre as regras para utilização no Fundo de Manutenção e Desenvolvimento da Educação Básica e de Valorização dos Profissionais da Educação (FUNDEB) ou nas resoluções sobre Atendimento Educacional Especializado (AEE), que inicialmente direcionou a possibilidade de atendimento para as escolas comuns (Decreto $\mathrm{n}^{\circ}$ 6.571, de 17/09/2008) e posteriormente a deixou aberta às escolas de educação especial (Decreto $\mathrm{n}^{\circ} 7.611$ de 17/11/2011). Tais movimentações atingiram outras políticas educacionais, como as relativas às questões da diversidade, no governo de Dilma Rousseff.

Durante a existência da Secretaria de Educação Especial os pressupostos de integração/inclusão se mostraram latentes e incisivos sobre as políticas sociais, em que se sinaliza a opção por um lócus preferencial de atendimento educacional especializado, a escola pública (BRASIL, 1988, 1996, 2007a), não sem o enfrentamento e fortalecimento das lutas empenhadas pelas instituições privadas de caráter filantrópico para que não perdessem espaço e influência entre essas políticas (BRASIL, 1988, 1996, 2007b). Instituições estas que representando a "tradição" (GARCIA, 2017) são marcadas por aspectos conservadores, com tendência a se apresentar como legítimos defensores dos direitos das pessoas com deficiência (JANNUZZI, 2004).

\title{
Secretaria de Educação Continuada, Alfabetização, Diversidade e Inclusão: aspetos da política de Educação Especial implementada
}

Ao longo do primeiro governo de Dilma Rousseff (2011-2014) realizaram-se cortes de gastos em diversos setores das políticas públicas (BBC, 2015; BRASIL, 2016; EL PAÍS, 2015). Essa iniciativa rendeu-lhe queda de popularidade, afastando o seu governo do até então apoio das classes populares e movimentos sociais, o que de certa forma o governo anterior conseguira manter (SADER, 2015). Como resultado do jogo entre garantir políticas sociais e incentivo estatal ao crescimento e ganhos dos setores financeiros desde 2003, tem-se no seu segundo mandato um pacto desmoronado entre as classes sociais (BRESSER-PEREIRA, 2015).

Em seu primeiro mandato, antes mesmo de ações mais concretas com base na austeridade fiscal, o Decreto $\mathrm{n}^{\circ} 7.480 / 2011$, de 16 de maio de 2011, reorganizou a Educação Especial na estrutura organizacional do Ministério da Educação à condição de diretoria de outra secretaria já existente, a SECAD, que passa a ser denominada 
Secretaria de Educação Continuada, Alfabetização, Diversidade e Inclusão (SECADI). Além da "Diretoria de Políticas de Educação Especial", a SECADI passou a ser composta pelas Diretorias de "Política para a Educação do Campo e Diversidade", de "Políticas de Alfabetização e Educação de Jovens e Adultos", e "Políticas de Direitos Humanos e Cidadania" (BRASIL, 2011, art. $2^{\circ}$ ).

No ano seguinte, o Decreto $\mathrm{n}^{\circ} 7.690 / 2012$ reorganizou a SECADI, que passou a ter a seguinte composição: "Diretoria de Políticas de Educação do Campo, Indígena, e para as Relações Étnico-raciais", "Diretoria de Políticas de Alfabetização e Educação de Jovens e Adultos", "Diretoria de Políticas de Educação em Direitos Humanos e Cidadania", "Diretoria de Políticas de Educação Especial", e "Diretoria de Políticas de Educação para a Juventude" (BRASIL, 2012).

Competia à Diretoria de Políticas de Educação Especial a implementação da Política Nacional de Educação Especial na Perspectiva da Educação Inclusiva (BRASIL, 2008), a oferta do AEE, a partir de ações de apoio técnico e financeiro, ações de formação continuada com os devidos materiais didáticos e a promoção da "transversalidade" e "intersetorialidade" das políticas de Educação Especial.

O período de existência da SECADI demonstra que o governo federal seguiu diretrizes esboçadas no primeiro e segundo mandatos do governo Lula. Certo de que, esses governos compartilharam princípios próximos: inclusão social pelo acesso a políticas compensatórias, ao consumo, a certa afirmação dos direitos sociais conquistados na Constituinte em 1988. Na concepção desses governos, "conciliar capital e trabalho" implicou em se fazer amplas alianças políticas, em seguir as diretrizes de organismos internacionais e colocar em prática uma lógica de inclusão social, sem alterar as estruturas econômicas que mantêm as desigualdades sociais acumuladas ao longo da história do país, a força de influência de diversos grupos de interesses sobre as políticas públicas (REBELO, 2016).

Mesmo com o contínuo aumento do número de matrículas de alunos com deficiência no ensino comum ${ }^{\ddagger}$ (REBELO, 2016), durante todo o governo houve continuidade da manutenção histórica das instituições privado-assistenciais pelo poder público (KASSAR; REBELO; OLIVEIRA, 2019).

Após o impeachment de Dilma Rousseff em 2016, tem-se início o governo Michel Temer (2016-2018). Nesse governo, marcado por intensa polarização política, ocorrem tentativas de "atualização" da Política Nacional de Educação Especial na Perspectiva da Educação Inclusiva de 2008 (BRASIL, 2008). As tensões materializamse por meio da aproximação de grupos vinculados às instituições privado-assistenciais e defensores de classes e escolas especializadas (incluindo escolas bilíngues) à SECADI, não sem disputas por parte de diferentes atores (organizações não governamentais, técnicos do Mistério da Educação, grupos de pessoas com deficiência e seus familiares, Ministério Público Federal, pesquisadores do campo da Educação Especial) que defendem o atendimento educacional especializado em escolas comuns, e que participaram ativamente das ações dessa Secretaria até 2016. Apesar desses embates, entre 2016 e 2018 a estrutura da SECADI permanece a mesma, com a Educação Especial apresentando status de Diretoria (MEC, 2018).

\footnotetext{
* No governo Dilma Rousseff, entre 2011 e 2014, há um incremento de 140.345 dessas matrículas (REBELO, 2016).
} 


\title{
Notas sobre a Secretaria de Modalidades Especializadas de Educação
}

No segundo dia de mandato do governo Jair Bolsonaro, o Decreto $\mathrm{n}^{\circ}$ 9.465/2019 em 2 de janeiro aprova a nova estrutura regimental do Ministério da Educação. Essa estrutura apresenta a Secretaria de Modalidades Especializadas de Educação, composta pela Diretoria de Acessibilidade, Mobilidade, Inclusão e Apoio a Pessoas com Deficiência; Diretoria de Políticas de Educação Bilíngue de Surdos; e Diretoria de Políticas para Modalidades Especializadas de Educação e Tradições Culturais Brasileiras (BRASIL, 2019a, Art. $2^{\circ}$ ).

Tem-se algo inédito no desenvolvimento das políticas de Educação Especial que é a criação de um setor voltado a uma deficiência específica, com mesmo nível de importância do setor destinado à Educação Especial em geral. Trata-se da "Diretoria de Políticas de Educação Bilíngue de Surdos", fruto da mobilização por parte dos movimentos de surdos desde o ano de $2017 .^{\S}$

Ao final do primeiro ano de governo, o Decreto $n^{\circ} 10.195$, de 30 de dezembro de 2019 aprova nova estrutura regimental do Ministério da Educação, remanejando e transformando cargos em comissão e funções de confiança. A Secretaria de Modalidades Especializadas de Educação passa a ter a seguinte estrutura organizacional: Diretoria de Educação Especial; Diretoria de Políticas de Educação Bilíngue de Surdos; e Diretoria de Modalidades Especializadas de Educação e Tradições Culturais Brasileiras (BRASIL, 2019b, Art. $2^{\circ}$ ).

Com o intuito de debater a formulação de políticas públicas para a formação de professores bilíngues para surdos, representantes das secretarias estaduais e municipais de educação dos 26 estados e do Distrito Federal participam do Seminário de Gestores Estaduais sobre Educação de Surdos, Surdocegos e Deficientes Auditivos e da Reunião Técnica de Dirigentes de Educação Especial dos estados e do Distrito Federal, promovidos pelo Ministério da Educação em agosto de 2019, com o intuito de "debater entre outros assuntos, a formulação de políticas públicas para a formação de professores bilíngues para surdos" (MEC, 2019a; 2019b).

Os eventos ocorreram de forma simultânea na sede da pasta. Na ocasião, foi abordada a "Nova Política Nacional de Educação Especial". A abertura contou com a presença da primeira-dama Michelle Bolsonaro e do ministro da Educação Abraham Weintraub. Ambos destacaram a importância do trabalho inclusivo realizado pela Secretaria de Modalidades Especializadas de Educação do MEC (MEC, 2019a):

\begin{abstract}
Estamos vivendo um novo momento para a educação de surdos no Brasil. E a prova disso é que vemos pessoas surdas ocupando cargos proeminentes no governo. Uma grande vitória alcançada foi a criação da Diretoria de Política Bilíngue para Surdos, aqui no MEC, trabalho que acompanho com muito interesse. Desejo que nossos programas, políticas e estratégias sejam para uma sociedade mais justa (Michelle Bolsonaro, em discurso feito na Língua Brasileira de Sinais, Libras). (MEC, 2019a).
\end{abstract}

O ministro da Educação destacou o papel de Michelle Bolsonaro na luta pelos direitos das pessoas com deficiência: "Conheci a primeira-dama na transição [...]. A primeira-dama brigou de forma muito suave e habilidosa para que esse governo fosse

\footnotetext{
$\S$ Disponível em: https://agenciabrasil.ebc.com.br/politica/noticia/2018-10/bolsonaro-usa-redes-sociais-ediz-que-nao-votou-contra-deficientes. Acesso: 6 abril 2020.
} 
um pouco melhor a cada dia que passasse" (MEC, 2019a). E acrescentou: "O Brasil e este governo ter uma abordagem toda especial nos faz mais humanos. Nós não podemos não ter um olhar fraterno para quem precisa de uma atenção especial para ser mais livre dentro das suas limitações, o máximo possível" (Abraham Weintraub, Ministro da Educação). (MEC, 2019b).

Mais uma vez, com o poder público se referindo à Educação Especial como questão de fraternidade, o pêndulo é direcionado para a filantropia e ações caritativas, o que remete às concepções conservadoras, historicamente presentes no discurso das instituições privado-filantrópicas. Chama a atenção também o fato de se vincular o acesso à Educação Especial à liberdade, o que acompanha o discurso hegemônico liberalizante e conservador sobre as políticas econômicas. Com exceção da política de atendimento aos alunos surdos, ainda não está claro qual o rumo a ser dado às políticas de Educação Especial em geral, a despeito de se falar em uma "nova política de Educação Especial".

\section{CONSIDERAÇÕES FINAIS}

Entre 1986 e 2020, foram verificadas algumas características constantes na Educação Especial brasileira. Uma refere-se à conformação de seu lugar na estrutura administrativa: tanto o CENESP, quanto a SESPE/SEESP, a SECADI e a atual Secretaria de Modalidades Especializadas de Educação foram e são órgãos gestores centrais, com mais ou menos autonomia, com a presença frequente da pressão de grupos privados (com maior ou menor participação).

O diálogo entre a administração pública e setores privados (particulares ou assistenciais-filantrópicos), como sociedade civil organizada, por um lado pode ser analisada como característica de processos democráticos, em que se espera a existência de disputas nas tomadas de decisão (CÔRTES, 2007; HOCHMAN, ARRETCHE; MARQUES, 2007). Por outro, pode ser indicativo de uma posição conversadora de manutenção de dependência econômica das instituições privadas aos recursos públicos, em detrimento do investimento na coisa pública, que colabora para o descrédito do lugar público como eficiente, adequado e patrimônio social.

Outra característica constante no período observado é o aumento do número de matrículas de alunos com deficiência e necessidades especiais nas escolas comuns, especialmente em escolas públicas. Este aspecto pode ser considerado um avanço, por propiciar o acesso à escola a milhares de alunos que historicamente estavam longe dela, contribuindo para a universalização da educação básica. No entanto, este movimento levanta também dúvidas quanto à permanência, à participação e ao desempenho desses alunos no sistema educacional (LAPLANE, 2015). Ao fomentar um serviço único para o atendimento educacional especializado na escola pública, como as salas de recursos multifuncionais (REBELO; KASSAR, 2017), os governos ampliam o atendimento especializado público, mas não concorreram com os atendimentos especializados que o setor privado oferece. Mesmo que não seja assumida explicitamente, a complementaridade dos serviços especializados, histórica na Educação Especial brasileira, vem sendo mantida. Dessa forma, algumas crianças continuam não fazendo parte da escola comum e "pertencendo" às escolas especiais.

Ao que indicam os documentos localizados, um momento que se distingue dos demais, em relação às parcerias históricas com as instituições privado-filantrópicas, foi 
o da formulação da Política Nacional de Educação Especial na Perspectiva da Educação Inclusiva de 2008, em que parece que não ter havido participação direta de representantes dessas entidades.

Se questões como a adequação das formas de atendimento ainda não estão resolvidas na Política Nacional de Educação Especial de 2008, privilegiar uma única categoria de deficiência para atenção do setor público, como parece ser a iniciativa do governo atual, não aponta caminhos para a ampliação dos direitos e acesso a diferentes modalidades de atendimentos pelas demais categorias de estudantes público-alvo da Educação Especial.

Para enfrentar os desafios atuais importa considerar as estruturas democráticas construídas a partir da Constituição Federal de 1988, em que espaços como os conselhos e as conferências de políticas públicas sejam considerados como lócus de interesses coletivos, esclarecimento e mobilização social.

\section{REFERÊNCIAS}

ALGEBAILE, M. E. B. Mecanismos regulatórios como elementos constitutivos da nova pedagogia da hegemonia. In: NEVES, L. M. W. (Org.). A nova pedagogia da hegemonia: estratégias do capital para educar o consenso. São Paulo: Xamã, 2005.

ALVES JUNIOR, A. G. C. TROVÃO, F. V. B. A educação entre a religião e a política: conservadorismo cristão e o homeschooling. Transversos: Revista de História. Rio de Janeiro, n. 17, Dezembro. 2019. pp. 36-60. Disponível em: https://www.epublicacoes.uerj.br/index.php/transversos/article/view/47405/31494.

APPLE, M. W. "Endireitar" a educação: as escolas e a nova aliança conservadora. Currículo sem Fronteiras, v.2, n.1, p.55-78, Jan/Jun 2002.

BAKHTIN, M. M. Estética da criação verbal. São Paulo: Martins Fontes, 1992.

BARBOSA, E. Opinião. Inclusão: Revista de Educação especial, Brasília, v. 4, n. 1, p. 51-58, jan./jun. 2008.

BBC. 'Ajuste fiscal é realidade', diz ministro da Educação sobre cortes, de 10 de julho de 2015.2015 .2 Disponível em: <http://www.bbc.com/portuguese/noticias/2015/07/150709_min_educ_ping_jf_lk>.

Acesso em: 13 maio 2016.

BEZERRA, G. F.; ARAÚJO, D. A. C. A. Novas (re)configurações no Ministério da Educação: entre o fio de Ariadne e a mortalha de Penélope. Revista Brasileira de Educação, v. 19 n. 56, jan./mar., 2014. 
BRASIL. Blog do Planalto. Ajuste fiscal, (tag). 2016. Disponível em: <http://blog.planalto.gov.br/assunto/ajuste-fiscal/>. Acesso em: 13 maio 2016.

1988.

Constituição da República Federativa do Brasil. Brasília, Senado Federal,

Decreto $n^{\circ}$ 9.465, de 2 de janeiro de 2019. Aprova a Estrutura Regimental e o Quadro Demonstrativo dos Cargos em Comissão e das Funções de Confiança do Ministério da Educação, remaneja cargos em comissão e funções de confiança e transforma cargos em comissão do Grupo-Direção e Assessoramento Superiores - DAS e Funções Comissionadas do Poder Executivo - FCPE. Brasília, 2019a.

Decreto $n^{\circ} 10.195$, de 30 de dezembro de 2019. Aprova a Estrutura Regimental e o Quadro Demonstrativo dos Cargos em Comissão e das Funções de Confiança do Ministério da Educação e remaneja e transforma cargos em comissão e funções de confiança. Brasília, 2019b.

- MEC. CCS. Presidência da República. Redefinição da educação especial. Brasília, 1985a.

MEC. CCS. Presidência da República. O resgate da educação especial. Coordenadoria de Comunicação Social. Brasília, 1985b.

MEC. LDBEN $n^{\circ}$ 9.394/96. Estabelece as diretrizes e bases da educação nacional. Brasília, 1996.

MEC. Portaria Normativa $n^{\circ} 13$, de 24 de abril de 2007, que dispõe sobre a criação do "Programa de Implantação de Salas de Recursos Multifuncionais". Brasília, 2007a.

MEC. SEESP. Política Nacional de Educação Especial. Brasília, 1994b.

MEC. SEESP. Política Nacional de Educação Especial na perspectiva da Educação Inclusiva. Brasília, 2008.

MEC. SEESP. Tendências e desafios da Educação Especial. Eunice M. L. Soriano de Alencar (Org.). Brasília: SEESP, 1994a.

Presidência da República. Decreto $n^{\circ} 72.425$, de 3 de julho de 1973, que cria o Centro Nacional de Educação Especial (CENESP), e dá outras providências. Brasília, 1973. 
Presidência da República. Decreto $n^{\circ} 7.480$, de 16 de maio de 2011, que Aprova a Estrutura Regimental e o Quadro Demonstrativo dos Cargos em Comissão do Grupo-Direção e Assessoramento Superiores - DAS e das Funções Gratificadas do Ministério da Educação e dispõe sobre remanejamento de cargos em comissão. Brasília, 2011.

Presidência da República. Decreto $n^{\circ}$ 7.690, de 2 de março de 2012, que Aprova a Estrutura Regimental e o Quadro Demonstrativo dos Cargos em Comissão e das Funções Gratificadas do Ministério da Educação. Brasília, 2012.

Presidência da República. Decreto $n^{\circ}$ 93.481, de 29 de outubro de 1986, que dispõe sobre a atuação da Administração Federal no que concerne às pessoas portadoras de deficiências, institui a Coordenadoria para Integração da Pessoa Portadora de Deficiência - CORDE, e dá outras providências. Brasília, 1986a.

Presidência da República. Decreto $n^{\circ}$ 93.613, de 21 de novembro de 1986, que extingue órgãos do Ministério da Educação, e dá outras providências. Brasília, 1986b.

Presidência da República. Decreto $n^{\circ} 94.806$, de 31 de agosto de 1987. Cria o Conselho Consultivo da Coordenadoria para Integração da Pessoa Portadora de Deficiência, e dá outras providências. Brasília, 1987.

Presidência da República. Governo de Fernando Henrique Cardoso. Câmara da Reforma do Estado. Plano Diretor da Reforma do Aparelho do Estado. Brasília, 1995.

Presidência da República. Lei $n^{\circ}$ 8.028, de 12 de abril de 1990. Dispõe sobre a organização da Presidência da República e dos Ministérios, e dá outras providências. Brasília, 1990.

Presidência da República. Lei $n^{\circ}$ 8.490, de 19 de novembro de 1992. Dispõe sobre a organização da Presidência da República e dos Ministérios e dá outras providências. Brasília, 1992.

Presidência da República. Lei $n^{\circ}$ 11.494/2007, de 20 de junho de 2007, que Regulamenta o Fundo de Manutenção e Desenvolvimento da Educação Básica e de Valorização dos Profissionais da Educação - FUNDEB e dá outras providências. Brasília, 2007b.

BRESSER-PEREIRA, L. C. Ajuste para poder governar. Nueva Sociedad, v. out., p. 1828, 2015. 
BUENO, J. G. S. Os programas da diretoria de políticas de educação especial (DPEE/SECADI/ MEC) para a inclusão escolar: as salas de recursos multifuncionais SRMS. Journal of Research in Special Educational Needs, n. 16, p. 172-177.

BUENO, J. G. S. Educação especial brasileira: integração/segregação do aluno diferente. $2^{\text {a }}$. ed. São Paulo: Editora da PUC/SP - EDUC, 2004. v. 1. 187p.

CORREIA, W. F. O que é conservadorismo em educação?. Conjectura: Filos. Educ., Caxias do Sul, v. 18, n. 2, p. 78-90, maio/ago. 2013.

CÔRTES, S. V. Viabilizando a participação em Conselhos de Política Pública Municipais: arcabouço institucional, organização do movimento popular e policy communities. In: HOCHMAN, G.; ARRETCHE, M.; MARQUES, E. (Orgs.). Políticas Públicas no Brasil. Rio de Janeiro: Ed. Fioruz, 2007.

CURY, C. R. J. A questão federativa e a educação escolar. In: OLIVEIRA, R. P.; SANTANA, W. (Orgs.). Educação e Federalismo no Brasil: combater as desigualdades, garantir a diversidade. Brasília: UNESCO, 2010.

EL PAÍS. Mais tributos e mais cortes: a conta da austeridade que o brasileiro vai pagar. $2015 . \quad$ Disponível em: <http://brasil.elpais.com/brasil/2015/09/15/politica/1442271444_522241.html, 15 set. 2015>. Acesso em: 13 maio 2016.

GARCIA, R. M. C. Disputas conservadoras na política de educação especial na perspectiva inclusiva. In: GARCIA, R. M. C. (Org.). Políticas de educação especial no Brasil no início do século XXI. Florianópolis: Núcleo de Publicações do CED, 2017. p. 19-66.

HOCHMAN, G.; ARRETCHE, M.; MARQUES, E. (Orgs.). Políticas Públicas no Brasil. Rio de Janeiro: Ed. Fioruz, 2007.

JANNUZZI, G. S. M. Algumas concepções de educação do deficiente. Revista Brasileira de Ciências do Esporte, v. 25, n 3, pp. 9-25, mai., 2004.

As políticas e os espaços para a criança excepcional. In: FREITAS, M. C.(org.) História social da infância no Brasil. São Paulo: Cortez: USF, 1997.

KASSAR, M. C. M. Mesa Redonda: Políticas de Educação Especial e implicações para as práticas escolares. In: VI Congresso Brasileiro de Educação Especial e IX Encontro Nacional dos Pesquisadores em Educação Especial. São Carlos, 2014. 
KASSAR, M. C. M.; REBELO, A. S.; JANNUZZI, G. S. M. Educação Especial como política pública: Um projeto do regime militar?. Archivos Analíticos de Políticas Educativas / Education Policy Analysis Archives, v. 27, p. 61, 2019.

KASSAR, M.; REBELO, A.; OLIVEIRA, R. Embates e disputas na política nacional de Educação Especial brasileira. Educação e Pesquisa, v. 45, p. e217170, 27 set. 2019.

LANNA JUNIOR, M. C. M. (Comp.). História do movimento político das pessoas com deficiência no Brasil. Brasília: Secretaria de Direitos Humanos, Secretaria Nacional de Promoção dos Direitos da Pessoa com Deficiência, 2010.

LAPLANE, A. L. F. O que os dados do Censo Escolar revelam sobre as barreiras à inclusão? Educação e Fronteiras On-Line, Dourados/MS, v.5, n.13 p.7-20, maio/ago., 2015.

LIBÂNEO, J. C. Democratização da escola pública. São Paulo: Loyola, 1990.

MAZZOTTA, M. J. S. Educação Especial no Brasil: histórias e políticas públicas. 3. ed. São Paulo: Cortez, 2001.

MEC. Colóquio: Política Nacional de Educação Especial na Perspectiva da Educação Inclusiva. Inclusão: R. Educ. esp., Brasília, v . 4, n. 1, p. 7-17, jan./jun. 2008.

MEC promove seminário nacional para discutir novas políticas para estudantes surdos. 2019a. Disponível em: $<$ http://portal.mec.gov.br/component/tags/tag/53151-seminario-de-gestores-estaduaissobre-educacao-de-surdos-surdocegos-e-deficientes-auditivos>. Acesso: 22 abril 2020.

. Seminário no MEC discute educação para surdos surdocegos e pessoas com deficiência auditiva. 2019b. Disponível em: <https://www.youtube.com/watch?v=1mp9zIxImQ8\&feature=emb_title>. Acesso: 22 abril 2020.

Política de educação especial deverá passar por atualização. 2018. Disponível em: http://portal.mec.gov.br/ultimas-noticias/202-264937351/62961-politica-deeducacao-especial-devera-passar-por-atualizacao. Acesso: 2 out. 2018.

MELETTI, S. M. F. Educação Escolar da pessoa com deficiência mental em instituições especiais: da política à instituição concreta. Tese. Doutorado em Psicologia Escolar e do Desenvolvimento Humano. USP, 2006.

ORLANDI, E. P. Análise de discurso. 6. ed. Campinas: Pontes, 2005. 
REBELO, A. S. A educação especial no Brasil: indicadores educacionais de atendimento especializado (1973-2014). 2016. Tese (Doutorado em Educação) Universidade Federal de Mato Grosso do Sul, Campo Grande, 2016.

REBELO, A. S.; KASSAR, M. C. M. Escolarização dos alunos da educação especial na política de educação inclusiva no Brasil. Inclusão Social (Online), v. 11, p. 56-66, 2017.

SADER, E. Profunda crise hegemônica no Brasil de hoje. Disponível em: $<$ https://www.brasil247.com/pt/blog/emirsader/207668/Profunda-crisehegem\%C3\%B4nica-no-Brasil-de-hoje.htm>. Acesso em: 23 dez. 2015.

SAVIANI, D. Escola e democracia. 8. ed. São Paulo: Cortez/Autores Associados, 1985.

SCHNEIDER, B. R. A privatização no governo Collor: triunfo do liberalismo ou colapso do Estado desenvolvimentista? Revista de Economia Política, v. 12, n. 1 (45), jan./mar., 1992.

SILVA, L. I. L. Pronunciamento do Presidente da República, Luiz Inácio Lula da Silva, na sessão solene de posse no Congresso Nacional, em $1^{\circ}$ de janeiro de 2003. Disponível em: <http://www.biblioteca.presidencia.gov.br/>. Acesso em: 17 jan. 2016.

SOUZA, F. F. S.; PLETSCH, M. D. Atendimento educacional especializado: das diretrizes políticas à escolarização dos alunos com deficiência intelectual. Educação $e$ Fronteiras On-Line, Dourados/MS, v.5, n.13, p.137-148, maio/ago., 2015.

Recebido: $18 / 05 / 2020$

Aprovado: 19/07/2020 